\title{
WEST AFRICAN INSTITUTE FOR TRYPANOSOMIASIS RESEARCH
}

T HE opening of the new West African Institute for Trypanosomiasis Research, at Kaduna, Northern Nigeria, on January 31, marks a noteworthy advance in the scientific development of the West African Colonies. The opening ceremony was performed by H.E. Sir John Macpherson, Governor of Nigeria, in the presence of a large gathering which included representatives of scientific and academic bodies in the United Kingdom and elsewhere.

In his opening address, Sir John Macpherson pointed out that trypanosomiasis not only causes much serious human sickness, but also-what is of even greater economic importance that this disease is responsible for very great annual losses among domestic stock, while over vast tracts of the West African territories the presence of the tsetse-fly prohibits the keeping of cattle of economic importance. Consequently, the cultivator is denied the use of animals for work and transport and is deprived of manure for his fields, while the diet of the population, both urban and rural, remains woefully deficient in meat and milk.

The scheme to develop this new research institute originated from recommendations made by Prof. T. H. Davey, of the Liverpool School of Tropical Medicine, after he had made an extensive tour of West Africa in 1945 at the request of the Tsetse-Fly and Trypanosomiasis Committee in London. Prof. Davey recognized the essential unity of research on human and animal trypanosomiasis and advised that an inter-territorial organization be set up to undertake research on "all aspects of the trypanosomiasis problem, human, animal and entomological". A Colonial Development and Welfare Research Scheme was made to cover capital and recurrent expenditure on the Institute for the first five-year period, amounting in all to approximately $£ 300,000$, of which twothirds was contributed by the British Government and the remaining one-third by the four West African Governments in agreed proportions.

Colonel H. W. Mulligan, formerly director of the Central Research Institute at Kasauli, was appointed the first director, and he went to West Africa towards the end of 1947 .

The new Institute, which has recently been completed, is organized in four Sections, two of which (Entomology and Epidemiology) have been sited at Kaduna, Zaria Province, where both human and animal trypanosomiasis are endemic, and two others (Protozoology and Veterinary Trypanosomiasis) at Vom, Plateau Province, where cyclical transmission of the disease does not occur under natural conditions.

The new laboratories at both centres are of simple design, well equipped and readily adaptable to al. most any purpose ; ample room has been left for expansion. Provision has been made for a specialized library with microfilm service, a central information bureau, a comprehensive photographic unit, a tsetse rearing centre, an animal breeding centre, spacious insectaries and fly-proofed animal houses. Facilities are therefore available for basic studies as well as for field investigations. A noteworthy feature is the provision of laboratory accommodation for visiting scientific workers in each Section, and already advantage has been taken of these facilities.

Living accommodation has been provided for twenty scientific workers and for one hundred technical and other assistants. It has been necessary to recruit expatriate staff for all the senior scientific posts ; but all other appointments are being filled by African personnel as suitable candidates become available. To ensure the maximum degree of freedom in the pursuit of its research activities, the Institute has been established as an autonomous body corporate with its own statutory managing committee.

The Institute has no direct responsibility for the actual conduct of trypanosomiasis control measures ; its primary function is to undertake research, in the laboratories and in the field, on all aspects of human and animal trypanosomiasis. It serves also as a clearing house for information on trypanosomiasis, as an advisory bureau, and as a training centre for expert technical personnel.

The inauguration of the research programme has proceeded pari passu with the development of the scheme ; but, owing to the absence of laboratory and living accommodation in the early stages, most of its work has hitherto been undertaken in the field. A considerable amount of work has already been done on the ecology of the riverine tsetse-flies of the savanna zones, G. palpalis and $G$. tachinoides, and the results obtained have had practical importance in achieving the elimination of these species in certain areas by the technique of complete or partial clearance of riverine vegetation. Very little is yet known of the tsetse of the high forest areas. Recent surveys in such localities, using new survey methods,

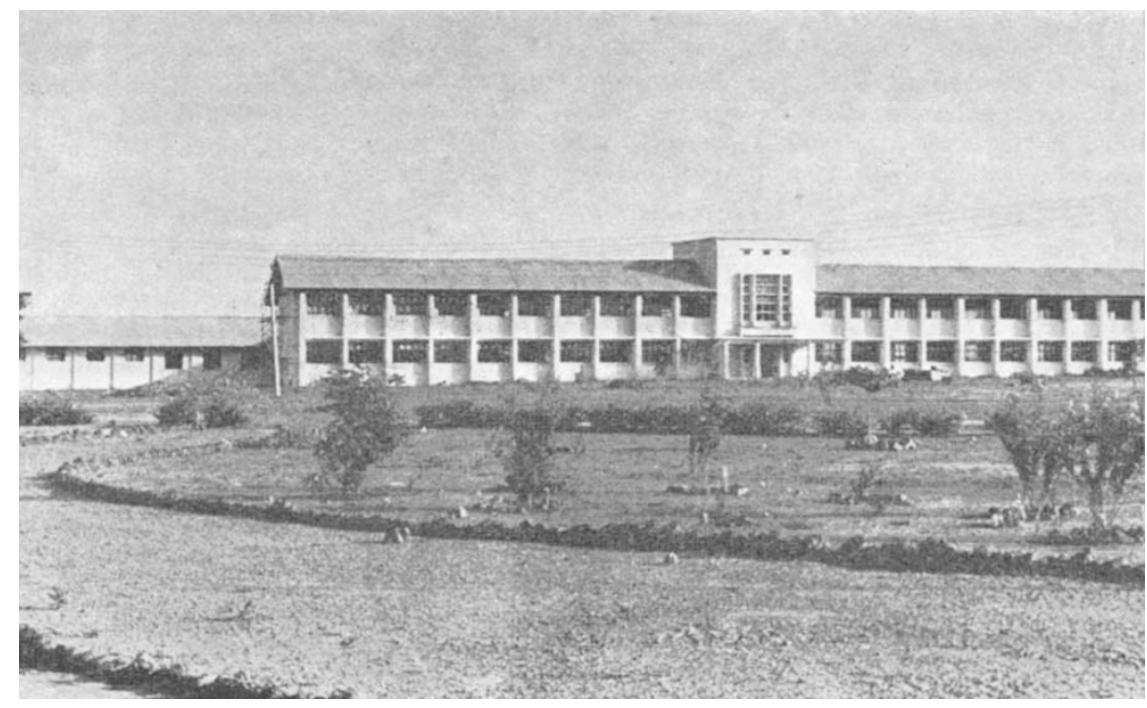

Main administrative aud laboratory buildings at Jaduna 
have revealed that certain species hitherto regarded as uncommon or even extremely rare are, in reality, not only prevalent but even possibly widespread. Nothing is as yet known of their economic importance.

Researches are in progress, or are projected, on many aspects of tsetse entomology. These include studies on the longevity, dispersal, breeding habits, feeding habits, infectivity, etc., of different species at various seasons. Laboratory experiments designed to supplement and serve as a check on observations made in the field are now being commenced, as well as further studies on the systematics and physiology of tsetse and such other biting flies as may be incriminated as vectors. A prerequisite to these investigations, and especially to the future work of the Protozoology Section, is the availability of large numbers of clean flies, and high priority has therefore been given to the laboratory rearing of tsetseflies on a large scale. The Entomology Section is also responsible for investigating the value of arboricides, insecticides and repellants in the control of trypanosomiasis.

Remarkably little work has hitherto been done on the epidemiology of either human or animal trypanosomiasis, and the study of this subject is the special responsibility of the Epidemiology Section. It has been possible to trace the origin of the severe and widespread epidemics of sleeping sickness which have occurred in Northern Nigeria during the present century to two endemic foci-one in the vicinity of the Niger-Benue confluence and the other in the Lake Chad basin. It has been shown that these epidemics were precipitated primarily by the dispersal of infected individuals consequent upon the settled conditions resulting from British occupation of the country, which facilitated the opening up of communications, the extension of agriculture and the introduction of such new industries as tin mining. There is no evidence that alteration in the prevalence or distribution of insect vectors played any appreciable part in the causation of these epidemics. Two isolated epidemics have recently been subjected to detailed investigation. Future work lies mainly in the elucidation of the intricate complexity of factors which favour or limit the spread of trypanosomiasis under natural conditions and will necessitate the careful study of selected communities, their environment and activities, in relation to the insect vector and the reservoir of infection.

In the veterinary sphere it is imperative to ascertain the true extent of the losses from trypanosomiasis which occur among domestic stock; to ascertain how, when and where such infections are acquired; to demarcate the danger zones; to study movements of stock in relation to tsetse ; and to consider ways and means of minimizing the losses which occur. This, in turn, involves a careful study of grazing areas, the migrations of nomadic cattle, the movements of trade cattle, and the conditions under which settled stock is maintained. Much more accurate knowledge is required of factors which may influence the severity of trypanosome infections in stock, such as heredity, nutritional deficiencies, intercurrent infections, immunizing procedures against other diseases, exposure to adverse environmental conditions, etc.

The protozoology of both human and animal trypanosomiasis requires much fuller investigation. Apart from further systematic studies on the trypanosomes, there is an urgent need for improved diag. nostic procedures, especially of cryptic infections; for studies on the life-history of the trypanosomes in both vertebrate and invertebrate hosts ; for immunological researches; and for ascertaining the factors governing the development, infectivity, transmissibility and pathogenicity of various species and strains of trypanosomes. Facilities are available for using cyclically transmitted strains in experiments of this kind. The chemotherapy and chemoprophylaxis of both human and animal trypanosomiasis are subjects which are currently receiving much attention and which are likely to continue to require constant research work. Experiments carried out during the past yoar have done much to indicate the circum. stances in which 'Antrycide' might be used in the prevention of cattle trypanosomiasis.

It is a constant concern of the Institute to devise and test such new measures for the control of trypanosomiasis as may be suggested by the acquisition of fresh knowledge in any of its many and varied spheres of research.

\section{CIRCULATION OF WATER IN THE OCEANS}

$A^{T}$

T a meeting at the Royal Astronomical Society on January 26, a Geophysical Discussion was held with the object of clarifying and co-ordinating our knowledge of the motion of large masses of water in the oceans. After opening contributions by an oceanographer and a meteorologist, a lively debate ensued in which oceanographers, meteorologists, astrophysicists, sailors and a hydraulic engineer all took part. Many will hope that in future greater attention will be given in Great Britain to this tantalizing and by no means 'useless' branch of science.

Dr. G. E. R. Deacon set the tone of the meeting with a critical review of the development of our knowledge of oceanic circulations. He referred to Croll's statement that "few subjects have excited more interest and attention than the cause of ocean circulation and yet few are in a more imperfect and unsatisfactory condition"; and he agreed with him that the principal reason why progress is still slow is that "the question is one which properly belongs to the domain of physics and mechanics", whereas few physicists of note have as yet given the subject special attention. Dr. Deacon's account contained many instances of progress being held up by lack of the appropriate specialized knowledge.

It was known before the eighteenth century that the temperature of the water near the bottom of the sea is low; but it was not until 1810 that Humboldt suggested that this cold water has come from the polar regions, sinking to the bottom because of its greater density. Later, in 1856, Maury extended this idea and asserted that all water movements, surface as well as deep, are caused by density differences.

Some time afterwards, these views were opposed by Croll (a geologist), who believed that the density differences were too small to account for the currents. He supported his assertions by referring to model experiments, and was led into a protracted argument with Carpenter (a biologist); but neither was ever able to convince the other, perhaps mainly because neither was able to get a proper grasp of the problem. (Croll's inferences from experiments are, in fact, invalid, because of the omission of a scale factor.) 